\title{
Design of Diesel Engine Adaptive Active Disturbance Rejection Speed Controller
}

\author{
Pan Weigang ${ }^{*}$ and Xiao Hairong
}

Department of Information Science \& Electronic Engineering, Shandong Jiaotong University, Shandong Jinan, 250357, P.R. China

\begin{abstract}
The ship main engine speed control system is a typical nonlinear system and it is uncertain characteristics, It is influenced by the wind, wave, flow etc. So it is difficulted to designed the diesel engine mathematical model. This paper presents a nonlinear mathematical model of ship main engine. Because the active disturbance rejection controller does not depend on the mathematical model of the system, this paper attempts to use the ADRC control technology to marine main engine speed controller. And fuzzy controller is used to modiffy the ADRC parameters to improve the adaptive ability of active disturbance rejection controller; So it is designed the fuzzy ADRC controller of ship main engine adaptive. The simulation results show that the ship main engine speed fuzzy ADRC controller has strong robustness, and speed switching is fast and smooth, so it can achieve high precision speed control.
\end{abstract}

Keywords: Diesel engine, Fuzzy, Active disturbance rejection controller.

\section{INTRODUCTION}

The performance and service life of marine main diesel engine performance depends largely on its control system. The ship main engine control system mostly adopts digital governor controller at home and abroad and it mainly used PID controller. The ship main engine speed control process is nonlinear, time varying and the necessary open parking, operator error operation and control object inevitably disturbed by the environment of uncertainty, this uncertainty should be seen as the important characteristics of the integrated control system. The traditional PID controller is difficult to meet the requirements of the control system, because the controller is usually in control system for constant coefficient and the interference of environment change is not too large conditions, So if the PID control system is used to the ship main engine speed control, it can't guarantee optimal performance, and even become stability.

Active disturbance rejection control technique (ADRC) is a new type of control technique which does not depend on the system model, and the sum of all the external and internal disturbances can be real-time estimation and compensation, so it has the advantages of small overshoot, fast response, precision high, strong anti-interference ability. Its algorithm is simple and easy to digital realization [1-8].

\section{DIESEL ENGINE MODEL}

The overall structure of the ship main engine speed control system is shown in Fig. (1).
Diesel engine used in this paper is MAN B\&W S60M (a large low speed diesel engine), Its mathematical model as follows:

$$
k T_{1} \dot{n}_{f}(t)+k n_{f}(t)=s(t-\tau)
$$

The actuator adopts DC servo motor, oil control mechanism composed of a rotating electromagnetic actuator, its mathematical model as follows:

$$
T_{2}^{2} \ddot{s}(t)+2 \xi T_{2} \dot{s}(t)+s(t)=n_{s}(t)
$$

Measurement of the speed detection unit directly affects the system's control precision, the ship generally use the magnetoelectric sensor, the mathematical model can be considered as a proportion of links.

In addition, the perturbation problem of ship main engine control is very complex, there are water depth, load, wind, current and wave. If the ship encountered storms at sea, sometimes the screw would be out of the water, the diesel engine load suddenly decreased, if the amount of oil spray pump can not be reduced, the engine speed would suddenly increased, or even reversed, when the load is suddenly increased, especially in low speed operation, if not timely supply increases, can cause the engine stop. The disturbance of the ship has a greater impact, when the controller is designed, which must be taken into account.

\section{DESIGN OF SHIP MAIN ENGINE FUZZY ACTIVE DISTURBANCE REJECTION CONTROLLER}

\subsection{The Diesel Engine ADRC Controller Design}

For marine main engine system shown in Fig. (1), double loop ADRC system in marine main engine will generally 


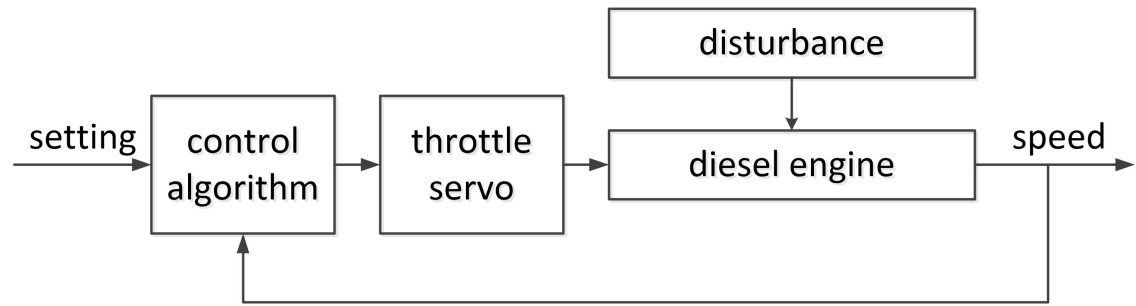

Fig. (1). Diesel engine speed control system block diagram.

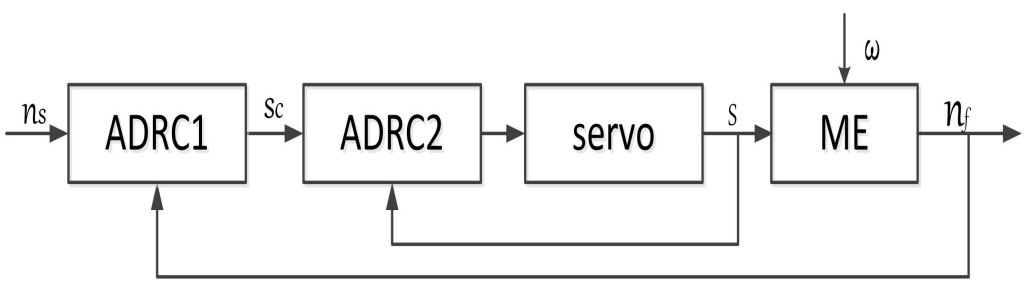

Fig. (2). Double loop of ship main engine ADRC controller.

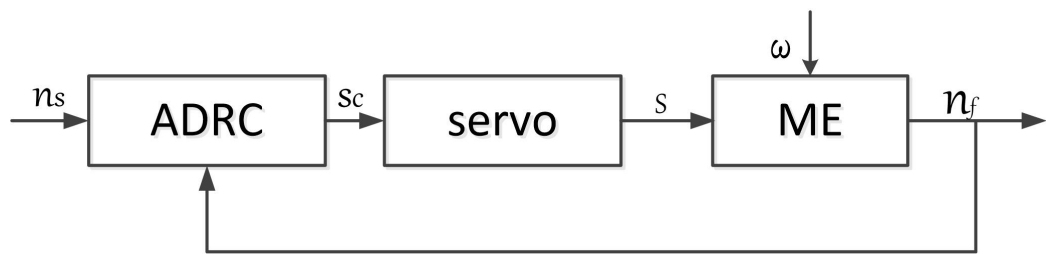

Fig. (3). Single loop of ship main engine ADRC controller.

designed as shown in Fig. (2) by the conventional design method. Where ADRC1 is the controller of the whole system in marine main engine ( 2 order), ADRC2 is the controller of servo mechanism ( 1 order), $n_{s}$ is expected to speed, $s_{c}$ for the expected displacement servo system, $n_{f}$ as the actual engine speed, the actual displacement of the servo mechanism $S$. If parameters of the controller is tunning From inner to outer ring respectively, the ADRC2 has 11 parameters, and ADRC1 had 15 parameters. It is difficult to design for so many parameters.

Taking into account the ultimate goal of the ship main engine controller design is to realize the speed accuracy and tracking, so the servo and the ship mathematical model can be considered as a whole, so as to simplify the controller design, the design of the structure as shown in Fig. (3), where ADRC is the two order ADRC the controller.

\subsection{Design of Adaptive Fuzzy Active Disturbance Rejec- tion Controller}

In practical application parameters of the active disturbance rejection controller would be tuning. The three main parts of ADRC(TD-nonlinear tracking differentiator, ESOextended state observer and NLSEF-nonlinear state error feedback control law) is designed independently of each other, so the three part parameters almost can be automatically generated respectively; Only $k_{p}$ and $k_{d}$ which are parameters of NLSEF be setting manually. So fuzzy logic control is used to achieve automatic adjustment of $k_{p}$ and $k_{d}$. In practical application, the two parameters of PD controller and nonlinear feedback of the tuning is very similar, $k_{p}$ is proportional coefficient, $k_{d}$ is differential gain. Therefore, we can design a fuzzy controller which can optimally approximate $k_{p}$ and $k_{d}$ automatically according to $e_{1}$ and $e_{2}$. So adaptive fuzzy active disturbance rejection controller is designed. The overall structure of the fuzzy ADRC control system is shown in Fig. (4).

According to Fig. (4), Where, $v_{1}$ is the track signal, $v_{2}$ is differential signal, $z_{1}, z_{2}$ are the estimation of output $y$ and its differential, $z_{3}$ is the estimation of total disturbance; $e_{1}, e_{2}$ are the error, $u_{0}$ is the output of NF, $b_{0}$ is the estimation of $b(t)$.

$e_{1}$ and $e_{2}$ are considered as input in the adaptive fuzzy active disturbance rejection controller, ADRC parameters $k_{p}$ 


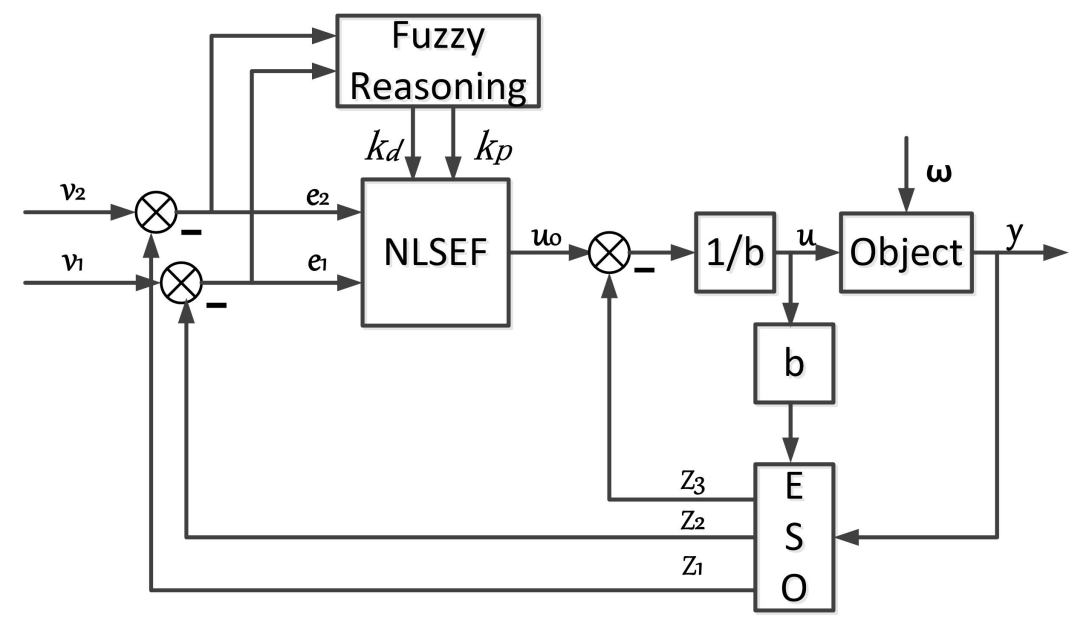

Fig. (4). Fuzzy adaptive ADRC controller block diagram.

Table 1. The fuzzy rule table of $k_{p}, k_{d}$.

\begin{tabular}{|c|c|c|c|c|}
\hline $\mathbf{K}_{\mathbf{p}} \mathbf{K}_{\mathbf{d}} \mathbf{e}_{\mathbf{1}}$ & NB & NS & ZO & PS \\
\hline \hline $\mathbf{e}_{2}$ & PB & PS & PS & PS \\
\hline NB & PS & PS & PS & NS \\
\hline NS & PS & PS & NO & NS \\
\hline PS & PS & ZO NS & NS & NS \\
\hline PB & ZO & NS & NS & NS \\
\hline
\end{tabular}

and $k_{d}$ are modified in tuning according to the fuzzy control rules, to meet the requirements to different time of ADRC parameter. The core of fuzzy controller design is technical personnel of knowledge and practical experience, and establish suitable fuzzy rule table, the established parameter selftuning fuzzy control table of $k_{p}$ and $k_{d}$ is shown in Table $\mathbf{1}$.

Fuzzy control subset is $e_{1}, e_{2}=\{N B, N S, Z O, P S, P B\}$, and supposing that $e_{1}, e_{2}$ and $k_{p}, k_{d}$ obey the normal distribution, degree of membershipcan be obtained according to the fuzzy sets. According to fuzzy membership assignment table the fuzzy subsets and the parameters of control model, application of fuzzy matrix synthesis reasoning design, the fuzzy matrix table of $k_{p}$ and $k_{d}$ can be designed. Finding out correct parameters into the formula, then the regulated $k_{p}$ and $k_{d}$ are obtained.

$k_{p}=k_{p}^{\prime}+\left\{e_{1}, e_{2}\right\}$

$k_{d}=k_{d}^{\prime}+\left\{e_{1}, e_{2}\right\}$
Combined with the ADRC parameter tuning principle and the ADRC formula, which can be adaptive fuzzy active disturbance rejection controller.

\section{SIMULATION RESULTS}

\subsection{Results of Constant Load and the Accuracy of Anal- ysis of Steady-State Conditions}

Fig. (5) is the speed of simulation results under setting the diesel engine $100 \%$ load.

The results shown that when the marine diesel engine is in high-speed operation under the $100 \%$ load, the maximum speed $n_{1}=911.8 \mathrm{r} / \mathrm{min}$, minimum speed $n_{2}=908.7 \mathrm{r} / \mathrm{min}$, average speed $n_{r}=910 \mathrm{r} / \mathrm{min}$, the rate of speed fluctuation is $v=\frac{n_{1}-n_{2}}{2 n_{r}} * 100 \%=0.17 \%$, it is less than class I accuracy specifications $(0.25 \%)$ of the china standard (GB/T34752008), so the governor control accuracy is better than the china standards. 


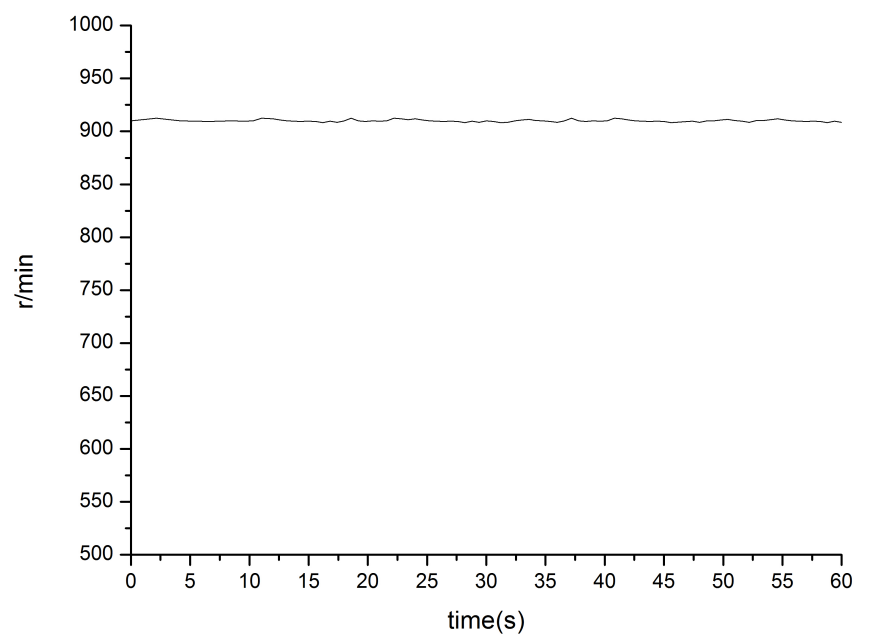

Fig. (5). Setting 100\% load speed simulation results.

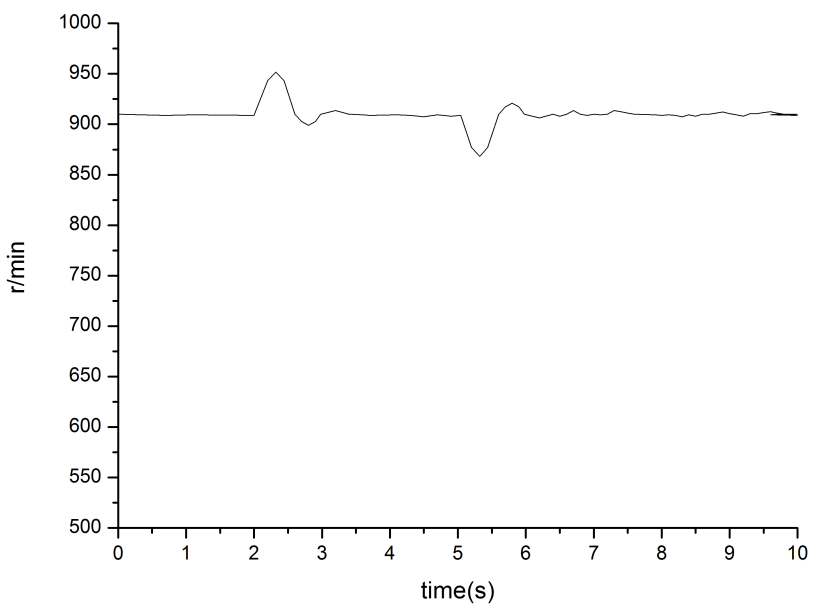

Fig. (6). Mutations in 100\% load simulation results.

Table 2. Two kinds of load to mutations simulation data.

\begin{tabular}{|c|c|c|c|c|}
\hline Load operating conditions & $\begin{array}{c}\text { Set speed } \\
/\left(\mathbf{r} / \mathbf{m i n}^{-1}\right)\end{array}$ & $\begin{array}{c}\text { Overshoot } \\
\text { Speed /(r/min }\end{array}$ & Transient speed regulation /\% & $\begin{array}{c}\text { Recovery } \\
\text { Time /s }\end{array}$ \\
\hline \hline Unload $100 \%$ load & 910 & 951.9 & 4.6 & 1.2 \\
\hline Sudden increase $100 \%$ load & 910 & 868.1 & 4.6 & 1.2 \\
\hline
\end{tabular}

\subsection{Results of the Load of Mutations Working Conditions and Robustness Analysis}

Fig. (6) is governor speed simulation results when the diesel engine is setted in the constant speed of $910 \mathrm{r} / \mathrm{min}$, and load unload or sudden increase of $100 \%$ due to the disturbance of the diesel engine. The two load data is shown in Table 2.

The experimental results shown that: the load in the mutation process, the instantaneous transfer rate (overshoot) of the intelligent governor is less than the china standard
(GB/T3475-2008) class I accuracy index 5\% , and settling time less than $2 \mathrm{~s}$, They all meet the requirements. Intelligent governor have a better robustness under the uncertainty of the environment.

\section{CONCLUSION}

This paper presents a design of the fuzzy adaptive ADRC for ship ME non-linear control. Simulation results show that this controller appears to be strictly robust to the non-linear characteristic of the ship, and system disturb- 
ances, and the system uncertainty. The process of speed switching is fast and smooth. So it works perfectly as a ship ME speed controller.

According to the simulation results, the ship main engine adaptive fuzzy ADRC controller has a strong robust for ship nonlinear characteristics and the system disturbance and uncertainty characteristics host switching control based on speed is fast, smooth, and maintain high accuracy,parameters of the wide adaptability, and it is an ideal ship the host controller.

\section{CONFLICT OF INTEREST}

The author confirms that this article content has no conflict of interest.

\section{ACKNOWLEDGEMENTS}

This work was financially supported by the Chinese Shandong Province Natural Science Fund Project (Number: ZR2013ZEM006), China Department of transportation Project (Number: 2014329817130) and Department of transportation of Shandong province Chinese Project (Number: 2013A16-04).

\section{REFERENCES}

[1] C. Lynch, H. Hagras, and V. Callaghan, "Embedded Type-2 FLC for Real-Time Speed Control of Marine \& Traction Diesel Engines", In: Proceedings of the IEEE International Conference on Fuzzy Systems, Reno, USA, May 2005, pp. 347-352.

[2] L. Guzzella, and A. Amstutz, "Control of diesel engines", IEEE Control Systems Magazine, vol. 4, pp. 53-70, 1998.

[3] J. Q. Han, "From PID Technique to Active Disturbances Rejection Control Technique", Control Engineering of China, vol. 9, no. 3, pp. 13-18, 2002.

[4] J. Q. Han, "Nonlinear State Error Feedback Control Law-NLSEF", Control and Decision, vol. 10, no. 3, pp. 221-225, 1995.

[5] E. Z. Song, J. Sun, and C. Yao, "Development and Experiment of Monitoring System for Remote-Controlled Marine Diesel Engine Powertrain", Chinese Internal Combustion Engine Engineering, vol. 31, no. 2, pp. 94-97, 2010

[6] D. Wu, and W. Tan, "A type-2 fuzzy logic controller for the liquid level process", In: Proceedings of the 2004 IEEE International Conference on Fuzzy Systems, Budapest, Hungary, July 2004, vol. 2, pp. 953-958.

[7] Y. L. Hang, "Using of Automatic Code Generation Technique to Develop Control Algorithm of Diesel Electronically Controlled System", Chinese Internal Combustion Engine Engineering, vol. 26, no. 2, pp. 9-12, 2005.

[8] Z. Gui-chen, and R. Guang, "Hardware-in-loop Simulation of Ship Speed Hybrid Error Regulator and its Stability Analysis", Journal of System Simulation, vol. 22, no. 2, pp. 353-356, 2010.

Received: July 01, 2015

Revised: August 10, 2015

Accepted: August 30, 2015

(C) Weigang and Hairong; Licensee Bentham Open.

This is an open access article licensed under the terms of the Creative Commons Attribution Non-Commercial License (http://creativecommons.org/licenses/by$\mathrm{nc} / 3.0 /$ ) which permits unrestricted, non-commercial use, distribution and reproduction in any medium, provided the work is properly cited. 